\title{
Challenging Architects in Education: the Smart Environments Integration Project
}

\author{
G. Maarten Bonnema \\ Department of Design, Production and Management, Faculty of Engineering Technology, \\ University of Twente, Enschede, The Netherlands \\ P.O. Box 217, 7500AE Enschede, The Netherlands \\ $+31534892548$ \\ and \\ Norwegian Institute for Systems Engineering, \\ University College of Southeast Norway, Kongsberg, Norway \\ g.m.bonnema@utwente.nl \\ Copyright (C) 2017 by G.M. Bonnema. Published and used by INCOSE with permission.
}

\begin{abstract}
Educating systems engineers is a challenge. Most attention in literature is on educating systems engineers on the job; after completion of an educational program at university. Architecting is even more difficult because it encompasses dealing with uncertainty, answering a very open problem and integrating disciplines. While on the job training remains important in developing systems engineers and architects, we present in this paper an effort to start this training already in university. We present systems design and engineering as embedded in a university program. The design of, and experiences with, an individual student project aimed at practicing systems architecting is treated. This involves the set-up of the project, students' results and their experiences.
\end{abstract}

\section{Introduction}

In Design and Engineering there is a growing need for people with a systems view. Because of the increased complexity of systems, and increased interconnectivity between systems, people with the ability to create, maintain and communicate the big picture are ever more needed.

In the Systems Engineering world, there is attention for the challenge of educating systems engineers, as illustrated by education tracks at conferences like the INCOSE international symposium (IS), the Conference on Systems Engineering Research (CSER) and the Systems of Systems Engineering conference (SoSE). Looking at papers presented in the IS2016 education track, most of the papers relate to educating and developing on the job, for instance (Jauregui, Pyster et al. 2016, Khan, Whitcomb et al. 2016, Whitcomb, Khan et al. 2016), that respectively discuss educational background and resulting systems engineering positions; the development of a competency model and the implementation thereof in a curriculum. Undergraduate teaching is explicitly addressed by (Simoni, Andrijcic et al. 2016), where the systems perspective for undergraduate students is developed, and for instance (Muller and Bonnema 2013) that deals with an undergraduate systems engineering course.

With the growing need for systems engineers, it is paramount to address more students to become systems engineers. This requires creating first awareness and interest in the work, 
then providing knowledge and competences. While it is often left to providing this knowledge and those competences to engineers in the working environment, as illustrated by the IS2016 papers, we believe, with (Simoni, Andrijcic et al. 2016, Muller and Bonnema 2013) that some of that work can already be accomplished in the education system (bachelor and master, or undergraduate and graduate).

This paper has the following goals:

- Show how systems engineering found a place in the bachelor and master programs in industrial design engineering at the University of Twente (The Netherlands); and

- Zoom in on an educational element in the master program that helps students become acquainted with systems architecting.

We chose the Industrial Design Engineering program at the University of Twente, as this is the place where we have accomplished most SE education. Also, the University of Twente, and in particular the Engineering Technology faculty, have a strong position in design directed systems engineering education and research.

We will dive into the education program first, look specifically at the systems design and engineering elements in the program. Then, we present the architecting challenge as presented to students. Further, we have conducted a survey among students to find out how the learning goals are met, and how learning to architect is perceived. The paper finishes with conclusions and directions for future work.

\section{The Industrial Design Engineering Curriculum}

The University of Twente (UT) started with an Industrial Design Engineering (IDE) program in 2001, resulting from extensive research on the added value of such a program (van Houten, Ruijter et al. 2000). Up till then, the only Dutch university offering such a program was the Delft University of Technology. Together with the start of the UT IDE program, the Eindhoven University of Technology initiated an IDE program. From the outset, the UT program aimed at educating designers, well-grounded in technology, that will be able to "Create the Future" (Eger, Lutters et al. 2004). In the bachelor program, time is spent on introducing students to systems engineering (Bonnema, Lutters-Weustink et al. 2005, Bonnema, Lutters-Weustink et al. 2016). With the introduction to systems design and engineering (SDE) in place, the challenge is to further educate those students interested in SDE in the master program.

That poses a difficult issue, because in general it is believed that becoming a systems engineer takes time. Reports mention 5-10 years on the job, building upon a relevant (engineering) education. Furthermore, the UT IDE program is in essence an industrial design engineering program, in contrast to specialized SE programs, like the ones offered by Stevens (Hoboken, NJ, USA) and the Norwegian Institute for Systems Engineering (Kongsberg, N).

In this Section, we will present the two parts of the program: Bachelor in brief; Master somewhat more elaborate. We focus on educating systems design and engineering. Further on in the paper, we will focus on a particular part that challenges junior engineers to do systems architecting. For clarity, architecting is (Bonnema 2008) the process of creating a system architecture that defines the parts constituting a system and allocates the system's functions and performance over its parts, its user, its super system and the environment in order to meet system requirements. Systems Engineering is an interdisciplinary approach and means 
to enable the full life cycle of successful systems. For this paper, consider systems design and engineering (SDE) the combination of systems architecting and engineering.

Bachelor (Undergraduate). After the recent overhaul of the program, the Bachelor Industrial Design Engineering bases like all UT Bachelor programs, on the Twente Education Model (TEM) (Twente 2015). This model aims at educating T-shaped professionals, with a strong basis in one or more disciplines (the vertical shaft of the T). Through the breadth (depicted by the top bar of the T), these professionals should be able to communicate with specialists in a wide range of disciplines.

The bachelor program (3 years) consists of 12 modules that each comprise a coherent set of teaching elements, with close resemblance to project led and design based education (Gómez Puente, van Eijck et al. 2015). Each module has a project that is used to apply the learnings from the other (often theoretical) module elements. There are modules that for instance go into user-centered design, product realization, and smart products. One of such IDE modules is described in detail in (Bonnema, Lutters-Weustink et al. 2016). That module in slightly modified form is also used in Electrical Engineering, Mechanical Engineering and other programs.

The Bachelor ends with an individual (capstone) project. The majority of the students do this project in-company, working on a real issue for the company. Projects vary from creating marketing material, via product or system design, to research in various design related fields.

Master (Graduate). After having received a Bachelor degree in IDE, students can (and often do) continue in one of the UT master programs. Next to the IDE master, students engage in programs on Mechanical Engineering, Sustainable Technology, Civil Engineering and other. Also, students enroll in master programs at other universities inside and outside of The Netherlands.

In case of the UT IDE Master program, there are different tracks:

- Human Technology Relations;

- Management of Product Development; and

- Emerging Technology Design.

For this paper, we focus on the Emerging Technology Design track (ETD) (Eger and Boer de 2005). Here, students can select one of several themes:

- Biomedical Product Design;

- Smart Environments and Virtual Reality;

- Sustainable Technology for Product Development;

- Product and Surfaces;

- Advanced Materials Engineering; and

- Structural Dynamics, Acoustics and Control

For each of these, the student dives into a specific technology, and investigates ways in which such a new technology can be introduced in the consumer market. A particular ability all students in ETD have to develop is communicating across disciplines. At the same time, a strong root in one (or two) technologies/disciplines is aimed for. This firmly shows the T-shaped professional, mentioned earlier. 
Common ground is created via the course "Sources of Innovation" (Eggink and Reinders 2013), that looks at ways to do innovation. In this case, specific attention is paid to investigating new markets and doing SWOT-analyses to identify potential applications and product-market combinations for new technologies.

The theme "Smart Environments and Virtual Reality" (SE\&VR) requires more attention for this paper. The name clearly indicates that we are looking at smart products and systems, possibly incorporating virtual (and/or augmented) reality. While true for all themes within ETD, for the SE\&VR theme particularly holds that students need to get rooted in technology, but with an outward looking attitude. Not only understanding the technology, but looking for, and reasoning about how, to apply the technology in new products and systems. Central is the development of "intelligent" systems and environments that exhibit learning behavior. While it remains philosophically intriguing whether systems can be called intelligent, the behavior we are looking for is that the system under design adapts to the user and use situation (Verbeek 2009).

In addition to the course "Sources of Innovation", students engage in Systems Engineering, and Scenario-based Product Design. These courses provide procedural information: how to do innovation, systems development, etc. Further, students need to understand dynamic behavior of systems. This can be found in a course on Dynamic Systems, but also from a course on Electric Vehicles and Electric Mobility.

Each student composes in consultation with the track-coordinator, a tailor-made program, where in addition to the courses above, each student dives into typically two (upcoming) technologies like virtual reality, speech recognition and processing, mechatronics, and so on. The education has to be completed before the student can start his/her capstone project. As in the bachelor, there is a large variety in types of projects. Most of the students do the capstone project in a company. Nevertheless, every master project has to be connected to ongoing research at the faculty.

A T-shaped professional, in addition to the technological rooting and cross-disciplinary communication, has to be able to integrate diverse technologies into a coherent product or system design. Learning this is often done on the job. But in the UT IDE program there is a particular project for practicing such integration: The Smart Environments Integration Project. This individual project, its goals, and students' experiences, are the main subject of this paper.

In order to place this project in context, we will briefly look at system design and engineering in the IDE curriculum.

\section{Systems Design and Engineering in the IDE Curriculum}

The IDE curriculum (bachelor and master) described above in brief, is a designer's program. Yet, there are shared competences between designers and systems engineers. When we look at for instance (Frank 2006, Frank and Kasser 2012) we see that a system thinker should be able to:

1. See the big picture;

2. Understand connections and closed loops;

3. Understand synergy;

4. Understand the system from multiple perspectives;

5. Think creatively; 

6. Step over details and handle uncertainty and ambiguity;
7. See implications of changes;
8. Understand a system when he/she sees it;
9. Understand analogies;
10. Understand limits to growth.

In particular abilities $1,2,4,5$, and 7 apply to designers and systems engineers alike. The other abilities are useful for both, but as Frank argues, essential for systems engineers.

In the IDE program, the basic way of working bases on SE principles like separating the solution from the problem, requirements analysis, modeling and creativity. This is the basis for the very first IDE course in the program: Introduction to Design Engineering (Eger, Bonnema et al. 2013).

By the end of the first year, the module on "Smart Products" elaborates on multidisciplinarity with input on computer programming, electronics and user interface design. Also, some SE elements are added (but still on introductory level), like embedded systems development and system integration. The second year has no explicit SE teaching.

The third year contains elective modules, where students can widen their view. The obligatory module "Systems in Context", described in the earlier mentioned (Bonnema, Lutters-Weustink et al. 2016) forms the main SE teaching. Please refer to that paper for in-depth information.

Students that engage in the SE\&VR theme in the IDE/ETD master with the aim to learn systems engineering, get a course in systems engineering, based on (Blanchard and Fabrycky 2011). This course adds the formal way of SE, as developed in the aerospace field, to the SE basis taught in the Systems in Context module.

As experienced SE's know, one really learns SE by doing it. It would be unwise to leave this doing until the final project, or even on the job. Therefore, we have developed a project where the SE competences come together. This project will be elaborated next.

\section{Challenging the Architect in Students}

Course Description. The Smart Environments Integration Project was developed around 2004 to allow students to practice systems architecting. The setup is that of an individual assignment to develop a system design, awarded with 5 European Credits (equivalent to 140 hours). The assignment is tailored to the student's program and interests. It is planned close to the end of the education, but before the capstone project. The expected outcome is a report, and preferably a prototype in one form or another. The course description is given in Figure 1.

The course aims are:

1. Perform system architecting on typical consumer systems.

2. Translate theoretical findings (as learned in courses) into a user-directed product.

3. Formulate and present a coherent and balanced system design.

4. Recognize opportunities of a new technology for use by consumers.

5. Balance stakeholders interests into a balanced system architecture. 


\section{INTRODUCTION}

The master track on smart environments and virtual reality has an essential component of joining different engineering disciplines into products that are useable and useful for customers. In this project two or three subjects are integrated into one system design.

\section{CONTENT}

A system architecture and design has to be developed. Depending on the courses followed in the first part of the master program, an assignment to define a system architecture is formulated by the coordinator. Techniques as taught in Systems Engineering and project competences from the Bachelor's curriculum in combination with tools and methods from research have to be used to arrive at a coherent and useable system design.

Aspects that have to be treated:

- Systems architecture

- Modules

- Interfaces

- User interfaces

- Context of use

Figure 1: The short course description.

There are no lectures in this project. However, study material is provided to the students. These include (Bonnema 2008, Maier and Rechtin 2009, Borches Juzgado 2010, Borches and Bonnema 2010, Bonnema 2011, Muller 2011). Also, reference is made to Muller's gaudisite (www.gaudisite.nl) as it contains a wealth of information on architecting. Further, the students are introduced to the project in an individual discussion with the teacher.

During the project, the student and teacher engage in a number of discussions. Core to these meetings is that the teacher on the one way helps the student to formulate the right questions, and point him/her in useful (solution) directions. On the other hand, the teacher will drag the discussion to a meta-level to help the student identify, adapt and develop his/her way of working. Issues that are discussed on meta level are for instance:

- What can you learn from the discussion on how to handle this kind of problems?

- How does thinking about the solution affect your understanding of the problem?

- What would you do differently if the product is not needed within two years, but in ten years instead (or the other way around)?

Example assignments. Over the years more than 25 of these projects have run. For an impression of the type of assignments, please consult Table 1 . While the assignments are tailored to the student, some assignments are reused, sometimes in a slightly modified way. Also, the assignments are artificial, in the sense that there is no direct company involvement or customer defined. Yet, we have seen that some of the earlier assignments showed up later 
on the market in real products (a smart multimodal travel planner with agenda integration, and a recycling advisor). This shows the realistic assignment set-ups. Also, we have now one assignment running where the student works on a problem emerging from ongoing research.

Table 1: A few example assignments.

\begin{tabular}{|l|l|}
\hline Title & Short Description \\
\hline \hline Smart Grid at Home & $\begin{array}{l}\text { Develop a system that a home owner can buy } \\
\text { and use to (1) save energy and (2) minimize } \\
\text { energy expenses. }\end{array}$ \\
\hline Drones in Traffic & $\begin{array}{l}\text { Help avoid and solve traffic jams by employing } \\
\text { drones. These could for instance create an } \\
\text { ad-hoc vehicle-to-infrastructure system. }\end{array}$ \\
\hline Office on the Go & $\begin{array}{l}\text { Develop an in-car system such that in an } \\
\text { autonomously driving car, the driver can do } \\
\text { useful office work, and at the same time keep a } \\
\text { watch on the car driving. }\end{array}$ \\
\hline Drones for Agriculture & $\begin{array}{l}\text { How can drones be used in agriculture in } \\
\text { sparsely populated areas? }\end{array}$ \\
\hline E-bikes support system & $\begin{array}{l}\text { Develop a system that on the one hand helps } \\
\text { E-bike users to plan their route using available } \\
\text { charging points. On the other hand, it should } \\
\text { stimulate people in the countryside to set-up a } \\
\text { charging point. }\end{array}$ \\
\hline
\end{tabular}

Space prohibits a verbatim copy of the assignment documents. In each case, the assignment consists of the following:

- General introduction, to address the connection between the student's interests and assignment;

- Intro to the field;

- Formulation of the foreseen system to be developed;

- Concretization of requested deliverables:

o Use scenario(s);

o Requirements and wishes;

o Architecture;

o Functional description;

o Feasibility, with connection to available technologies, or technologies under development; and

o If possible a simulation model or prototype.

- Reference to relevant literature.

Results. Students write a report (typically 30-60 pages) where they present and support the created system design, plus appendices. An often created appendix is an A3 Architecture Overview (Borches Juzgado 2010, Borches and Bonnema 2010) of the created system. Figure 3 shows an example of such an A3 Architecture Overview, in this case for the drones in agriculture (Table 1). A histogram of the grades obtained is shown in Figure 2. 


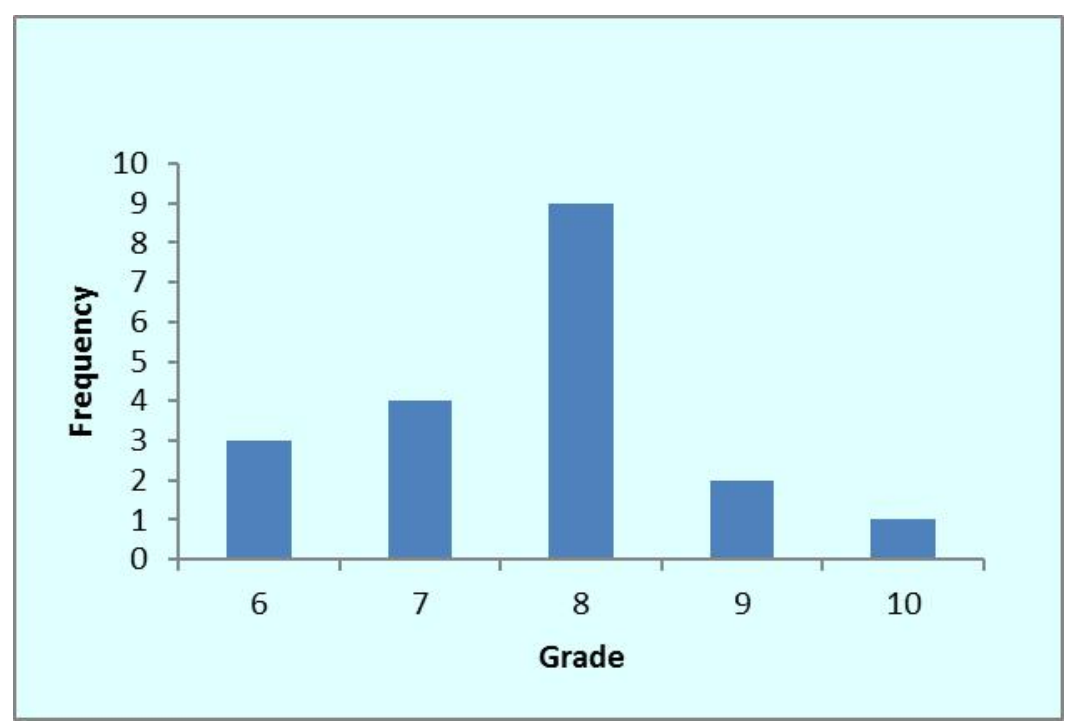

Figure 2: Histogram of results $(n=19)$. 6 is just sufficient, 10 is outstanding. Note that a grade below 6 results in the student not passing. Then the work can be improved (once) and a maximum grade of 6 can be obtained.

Other intermediate results and deliverables are:

- Key drivers of the system under design;

- Functional descriptions;

- N2 diagrams (both functional and modular ones);

- Concept selection charts; and

- Context and stakeholder diagrams.

\section{Students' Experiences}

To get feedback on the project from students, a short survey was held among students (both in-progress with the project, and those that already completed it). The purpose was to find out whether the goals stated in the course description are met, whether the students are actually doing architecting, whether the meetings work, and whether students are sufficiently challenged. This Section describes the survey and the results.

The survey is set-up using an online platform (thesistools.com). 19 students have been addressed via e-mail, of which 2 emails bounced because of incorrect or outdated email addresses. All responses are anonymous.

The survey consists of eight questions:

- two introductory questions about the student,

- two questions about learning elements,

- one about the assignment,

- two about the usefulness of the project, and

- a final open question where the respondents can enter remarks.

In the remainder of this Section, we present the questions and the results. In the next Section, the results are discussed. 


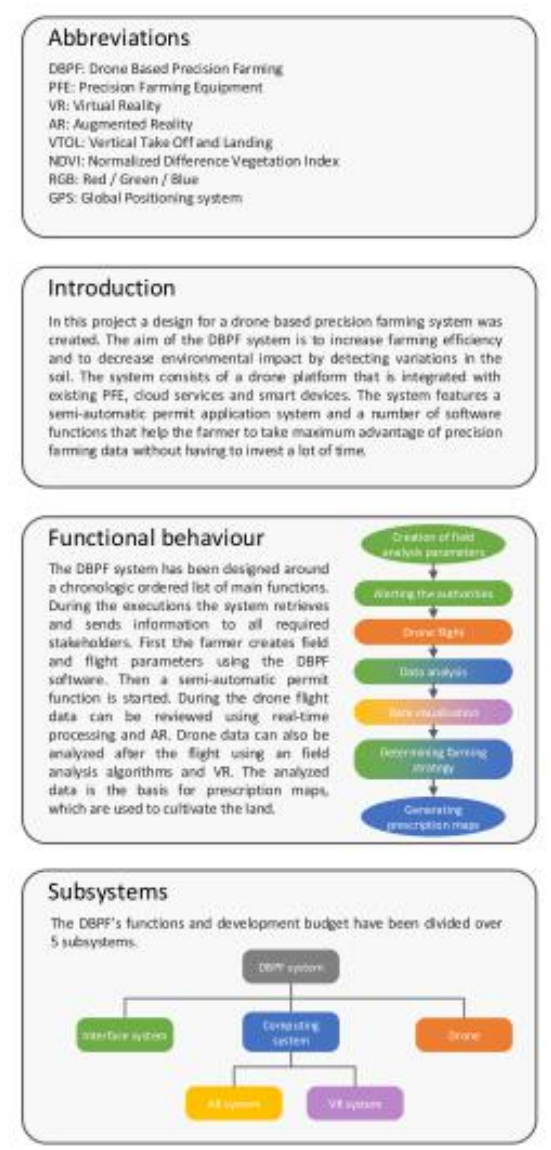

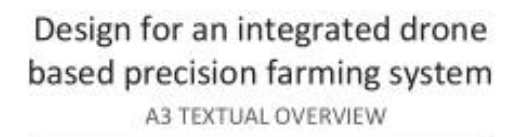
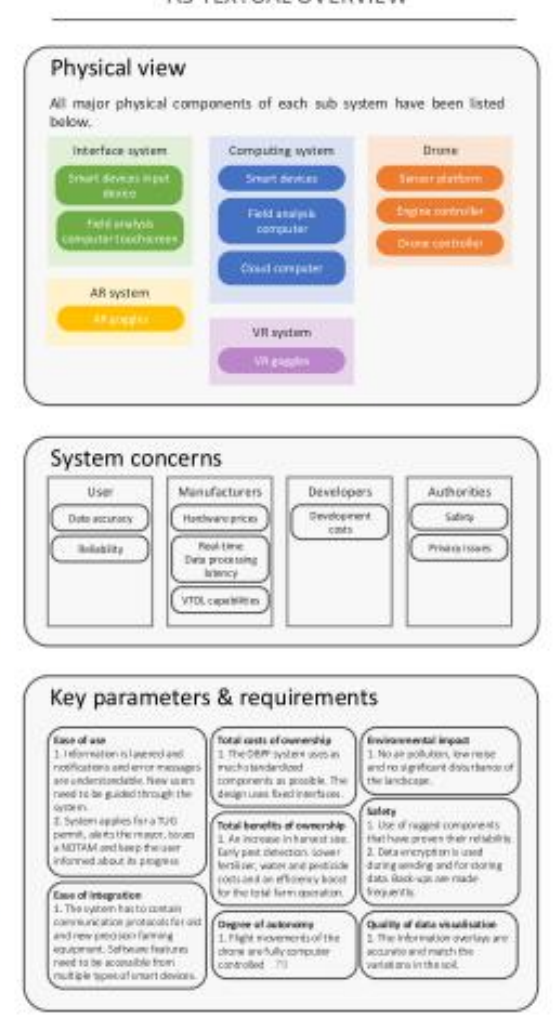
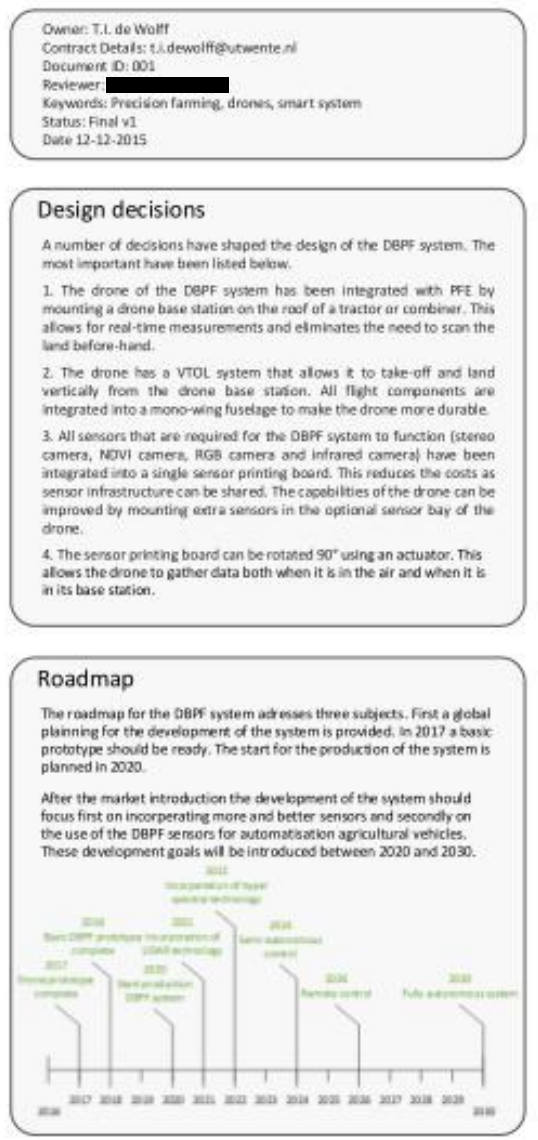

Figure 3: A3 Architecture Overview (textual side) of a drone supported precision farming system (by T. de Wolff).

The respondents. From the 17 successful survey invitations, 11 students filled out the survey. This number is too low to do advanced statistics. However, it is large enough to draw conclusions about the project. Also, note that relative to the approximately 25 assignments handed out over a period of 12 years, 11 respondents forms a significant ratio.

Of the 11 respondents, ten are from the SE\&VR track, one is from another ETD track. Six out of 11 respondents have already completed the IDE program, four are in progress with the project, one respondent has completed the project, but is still in the IDE program.

The learning elements. Two questions relate to the learning elements: one that directly asks the student what he/she perceived as most important learnings, and one about the usefulness of the meetings with the teacher.

The results for the first question (What are the most important learnings for you (multiple answers possible)?), are shown in Table 2. Per respondent, an average of 6.5 learning elements was acknowledged. There was one respondent $(\mathrm{X})$ who mentioned only one learning element. All others reported five or more learning elements.

The other question about learnings relates to the student-teacher meetings, with results shown in Table 3. Here, the average number of contributions of the meetings was 2 . One respondent (again $\mathrm{X}$ ) reported no contribution. 
The assignment. We asked the respondents how they rate the assignment on a scale from simple (1) to challenging (5). The results are as shown in the histogram in Figure 4.

In addition to the histogram, we calculated the net promoter score (NPS) for this question (Reichheld 2003):

$$
\text { NPS = Number of Promoters }- \text { Number of Detractors. }
$$

For this question, the Detractors have scored 1 or 2, Passives are at 3 or 4 and Promotors have scored 5 . Then the NPS can be calculated to be 2 .

Overall usefulness. Two questions relate to the usefulness as perceived by the respondents:

- Do you think the smart environments integration project provided added value to your education? (Scale from "Yes, definitely" to "No, not at all"); and

- What is your overall rating of the Smart Environments Integration Project? (Scale from "Essential" to "Useless").

Table 2: Results showing the learning elements as perceived by the students.

\begin{tabular}{|l|l|}
\hline What are the most important learnings for you (multiple answers possible)? \\
\hline doing a project from an open problem & 8 \\
statement & 5 \\
managing my time & 2 \\
writing the report; structuring information & 7 \\
dealing with uncertainty & 4 \\
defining the goal (myself) & 8 \\
creating a system architecture & 4 \\
presenting a system architecture & 3 \\
discussing about the architecture & 3 \\
inventory the stakeholders & 3 \\
taking multiple stakeholders into account & 4 \\
inventory the context & 4 \\
making tradeoffs & 4 \\
integrating different disciplines into one & \\
system design & 2 \\
recognize opportunities in new technologies & 4 \\
selecting Systems Engineering tools and & \\
techniques & \\
applying Systems Engineering tools and & \\
techniques & \\
other: please specify & \\
\hline
\end{tabular}


Table 3: Results showing how respondents experienced the student-teacher meetings.

\section{The meetings with the teacher (multiple answers possible):}

helped me to move on

helped me to see the big picture

helped me with information on how to architect

helped me to think on a more meta-level about architecting

helped me to clarify the problem

helped me to define the solution

were not very useful

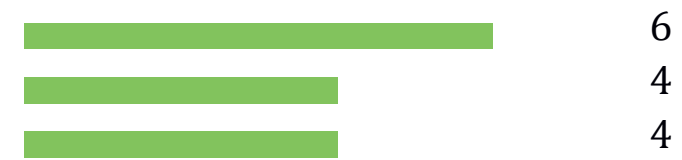

2

6

0

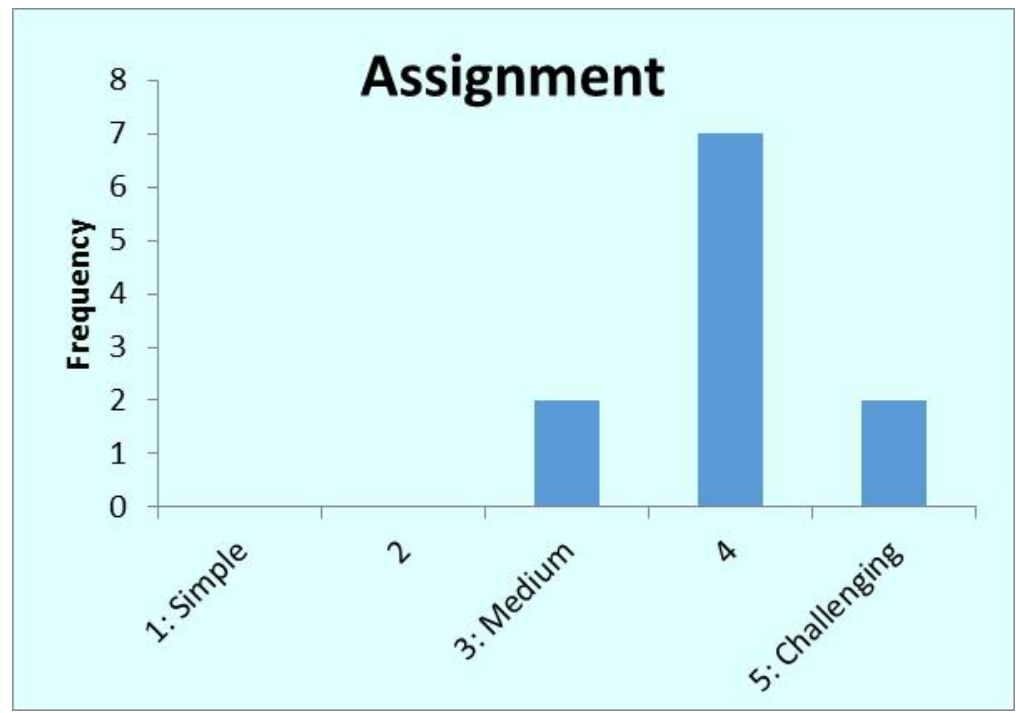

Figure 4: The challenge of the assignment, as perceived by the respondents.

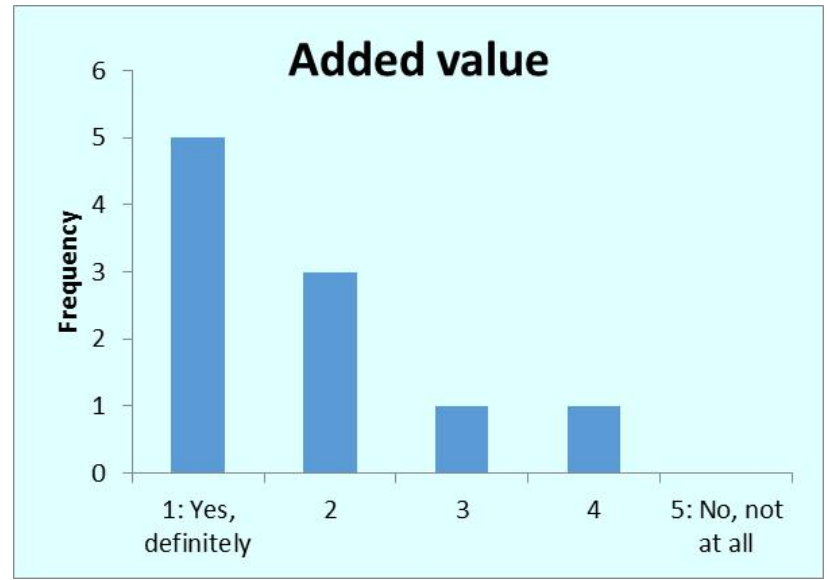

a: The perceived added value of the integration project

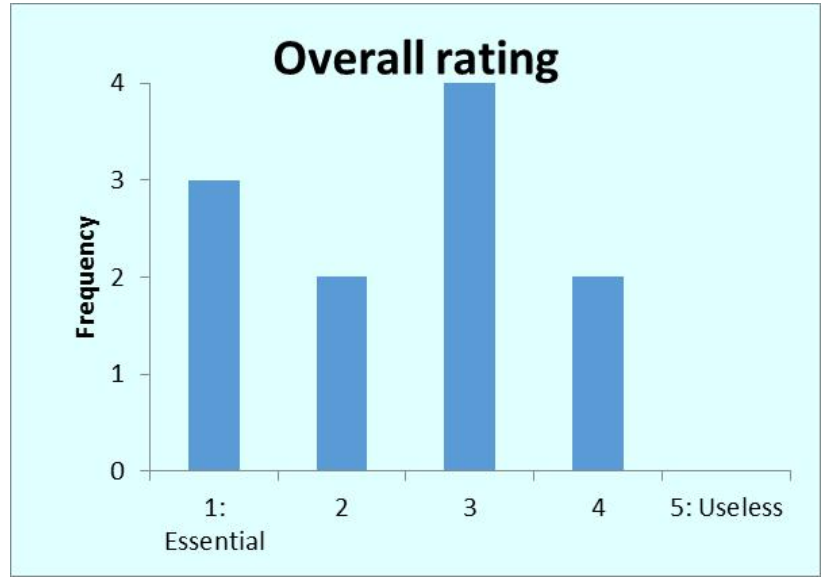

b: the overall rating of the project.

Figure 5: Result of two questions about the usefulness of the integration project. 
For these two questions, we also calculated the net promoter score. For both the added value question (Figure 5a) and the overall rating (Figure 5b), the promoters are 1 (Yes, definitely, resp. Essential), the detractors 4 and 5 (No, not at all, resp. Useless), and 2 or 3 correspond to the passive category. This results in an NPS for the added value of 4 . The overall rating has an NPS of 1.

Remarks and feedback. The final question was an open question where respondents can report at will. The remarks given relate to the time that has passed since completing the project, and requests for more information in advance. One respondent mentioned the fact that the assignment is made up, resulting in absence of actual stakeholders. One student remarked that the project takes a considerable amount of time. From direct discussions with students, the teacher heard this more often. In most cases, the students do not see this as a problem as they appreciate the challenge.

\section{Discussion}

First, let us look at the perceived learning outcomes, as shown in Table 2 and 3 . The most achieved learning outcomes are:

- doing a project from an open problem statement (8)

- dealing with uncertainty (7)

- creating a system architecture (8)

- applying Systems Engineering tools and techniques (7)

In particular dealing with uncertainty is an important ability for architects. Here 7 out of 11 students find this an important learning for themselves. Also the open problem statement and application of SE tools and techniques show that the students practice the architect's tasks. Of course, the creation of a system architecture is an important result.

Looking at the complete list of learnings in Table 2, we see that all items are ticked by at least two respondents. Important architecting activities like making trade-offs (4) and integrating different disciplines (also 4) were recognized. Most respondents recognize a large number of learnings (five or more of the listed 16). This shows the project contributes to the student's education.

The project runs close to the end of the students' master curriculum. It is therefore a surprise to see that students value the opportunity to structure information, write a report, and manage their time. One would expect that the students have had ample opportunity earlier in the bachelor and master curriculum.

Looking at Table 3, the main help from the student-teacher meetings are on a practical level (problem clarification, move on). Yet, the architecting related issues (how to architect, see the big picture) were acknowledged. Also information on how to architect was appreciated by 4 students. Note, that no student checked "helped me define the solution". This is a good result, as obviously the student has to define the solution. Two respondents explicitly recognized the meta-level in the discussions. In general, all students saw value in the meetings, as no one checked "were not very useful", and the average number of contributions reported was 2 . This average is negatively influenced by one respondent who did not see the learnings in the project, nor did he/she recognize any contributions of the student-teacher meetings. 
The assignment is seen as quite challenging by most students. This can be seen as useful, because if students are not challenged, they can meet the goals using previous knowledge and competences. However, if these do not suffice, new tools and techniques are valued and adopted.

Finally, looking at the overall evaluation, we see a difference in NPS for two related questions:

- Do you think the smart environments integration project provided added value to your education? Resulting in an NPS of 4; and

- What is your overall rating of the Smart Environments Integration Project? Resulting in an NPS of 1.

Apparently, the respondents see the added value, but also see some shortcomings in the way the project runs now. In particular (based on the open remarks in the final question), more structure in both the material treated and the process of doing the project is requested. Fortunately, both questions result in a positive NPS, meaning an overall positive evaluation (Reichheld 2003).

The students' grades (Figure 2) are balanced around the 8. One student did a particularly nice and complete job, and created a nice simulation model/prototype. He was awarded a 10. Note that as the survey was completed anonymously, it is impossible to identify any relations between grade and survey answers.

The course aims (see just before Figure 1) are mostly met, with the exception of \#4: "Recognize opportunities of a new technology for use by consumers". This, in fact, is done by the teacher formulating the assignment. While the students have to dive into new technologies, and investigate the opportunities and limitations, the way of use is largely given in the assignment. While some students come up with innovative ideas, this is not the general case. It will be interesting to find ways to change this so that the students will meet the learning goal.

\section{Conclusions}

As main conclusion we can state that the Smart Environments Integration Project helps student to practice systems architecting. Dealing with open problems, uncertainty and making trade-offs are core architecting competences, and student value the opportunity to try them out in a safe environment. We have not checked whether students that have completed this project are actually adopting systems engineering tasks sooner and more easily. Yet, because the students have practiced systems architecting, building up architecting experience starts sooner. By selecting a challenging problem that fits the student's interests, students are willing to spend (a significant amount of) time in this practicing architecting.

While it turns out to be difficult in the present set-up to challenge students to find applications for new and upcoming technologies, most learning goals appear to be met for most students. The open problem statement resembles real-life architecting problems. Yet, the assignments are artificial. An experiment with a real architecting problem needs further monitoring.

The student-teacher meetings have added value (Table 3), but their role and function require some adjustment. In particular, the balance between general project assistance and specific architecting knowledge, competences and abilities needs to be improved. Earlier in the 
program, the importance of being able to structure one's own work and write reports needs to be stressed.

Future Work. We will work on adjustments in the project. In particular, more structure in the student-teacher meetings is needed. Compilation and use of a checklist is seen as useful. Also, learning goal \#4 (Recognize opportunities of a new technology for use by consumers) needs more attention so that students can meet this goal. Alternatively, the goal needs to be reformulated or modified. We will also consider following the students in their further career to see whether and if so, how, they adopt systems engineering jobs.

\section{References}

Blanchard, B. S. and W. J. Fabrycky (2011). Systems Engineering and Analysis. Upper Saddle River, New Jersey, Prentice Hall.

Bonnema, G. M. (2008). FunKey Architecting - An Integrated Approach to System Architecting Using Functions, Key Drivers and System Budgets. PhD PhD-thesis, University of Twente.

Bonnema, G. M. (2011). "Insight, innovation, and the big picture in system design." Systems Engineering 14(3): 223-238.

Bonnema, G. M., I. F. Lutters-Weustink and J. Jauregui Becker (2016). A Decade of Teaching Systems Engineering to Bachelor Students. Systems of Systems Engineering 2016 (SoSE). G. Muller and G. M. Bonnema. Kongsberg, Norway, IEEE.

Bonnema, G. M., I. F. Lutters-Weustink and F. J. A. M. van Houten (2005). Introducing Systems Engineering to Industrial Design Engineering Students with hands-on experience. 18th International Conference on Systems Engineering (ICSEng05). Las Vegas, IEEE Computer Society: 408--413.

Borches Juzgado, P. D. (2010). A3 architecture overviews : a tool for effective communication in product evolution. PhD PhD-thesis, University of Twente.

Borches, P. D. and G. M. Bonnema (2010). A3 Architecture Overviews - Focusing architectural knowledge to support evolution of complex systems. 20th Annual INCOSE International Symposium - IS2010. Chicago.

Eger, A., G. M. Bonnema, E. Lutters and M. C. v. d. Voort (2013). Product Design, eleven international publishing.

Eger, A. O. and A. Boer de (2005). Emerging technology design; A new master course aimed at bringing emerging technologies its break through applications. Crossing Design Boundaries: Proceedings of the 3rd Engineering \& Product Design Education International Conference, 15-16 September 2005, Edinburg. P. Rodgers, L. Brodhurst and D. Hepburn. London, Taylor \& Francis: 121-126.

Eger, A. O., D. Lutters and F. J. A. M. van Houten (2004). 'Create the Future'. International Engineering and Product Design Education Conference. Delft, The Netherlands.

Eggink, W. and A. Reinders (2013). Explaining the design \& styling of future products. 15 th International Conference on Engineering and Product Design Education, Design Education Growing our Future, Dublin, 5-6 September 2013. Dublin: 785 -.

Frank, M. (2006). "Knowledge, abilities, cognitive characteristics and behavioral competences of engineers with high capacity for engineering systems thinking (CEST)." Systems Engineering, The Journal of the International Council on Systems Engineering 9(2): 91-103.

Frank, M. and J. Kasser (2012). Assessing the Capacity for Engineering Systems Thinking (CEST) and Other Competencies of Systems Engineers. Systems Engineering - Practice and Theory. P. B. Cogan, InTech. 
Gómez Puente, S. M., M. van Eijck and W. Jochems (2015). "Professional development for design-based learning in engineering education: a case study." European Journal of Engineering Education 40(1): 14-31.

Jauregui, C., A. Pyster, D. Henry, N. Hutchison and C. Wright (2016). "Insights on the Experiences and Education of INCOSE-Certified Expert Systems Engineering Professionals and Chief Systems Engineers." INCOSE International Symposium 26(1): 480-494.

Khan, R., C. A. Whitcomb, C. White, D. Grambow and J. Delgado (2016). "The U.S. Department of the Navy's Systems Engineering Career Competency Model: Identification of Proficiency Levels and Career Path Modeling." INCOSE International Symposium 26(1): 125-137.

Maier, M. W. and E. Rechtin (2009). The art of systems architecting. Boca Raton, FL, CRC Press. Muller, G. (2011). Systems Architecting: A Business Perspective. Boca Raton, FL, CRC Press. Muller, G. and G. M. Bonnema (2013). Teaching Systems Engineering to Undergraduates; Experiences and Considerations. INCOSE IS2013. Philadelphia, INCOSE.

Reichheld, F. F. (2003). "The One Number You Need to Grow." Harvard Business Review 81(12): 46-55.

Simoni, M., E. Andrijcic, B. Kline and A. Bernal (2016). "Helping Undergraduate Students of any Engineering Discipline Develop a Systems Perspective." INCOSE International Symposium 26(1): 495-511.

Twente, U. o. (2015). The Twente Education Model. Enschede, University of Twente.

van Houten, F. J. A. M., C. T. A. Ruijter, R. v. Dijk, J. van Dijk, H. J. M. Geijselaers, H. Grunefeld, E. E. G. Hekman, F. G. M. Kokkeler, D. J. Schipper and S. H. Visser (2000). Report for the Advisory Committee for new Curricula. Enschede, University of Twente

Verbeek, P.-P. (2009). "Ambient Intelligence and Persuasive Technology: The Blurring Boundaries Between Human and Technology." Nanoethics 3(3): 231-242.

Whitcomb, C. A., R. Khan and C. White (2016). "Curriculum Alignment Use Case for Competency Frameworks at the Naval Postgraduate School." INCOSE International Symposium 26(1): 105-114.

\section{Biography}

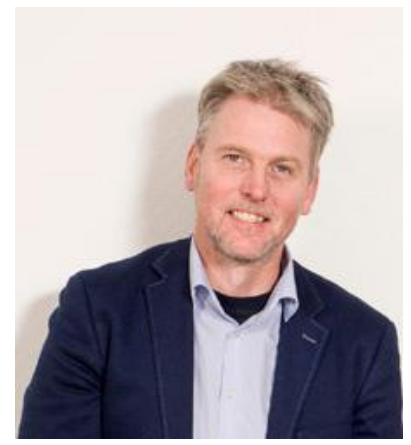

G. Maarten Bonnema is an associate professor in multidisciplinary systems design at the Department of Design, Production and Management of the Faculty of Engineering Technology at the University of Twente. He has worked as a Systems Engineer at ASML. His research aims at supporting system designers, conceptual design and mechatronic design by improving multidisciplinary communication. Also systems thinking is researched. An overview of publications can be found at http://www.tinyurl.com/MaBoPubs. He has a broad teaching expertise spanning design in general, industrial design, and systems engineering. He also holds a position as associate professor at the Norwegian Institute for Systems Engineering in Kongsberg, Norway. 